\title{
FETOMATERNAL OUTCOME IN ECLAMPSIA
}

\author{
Rayamajhi A K', Uprety D*, Agrawal A*, Pokhrel H*
}

\section{ABSTRACT}

A cross-sectional hospital based study was conducted to analyze the relation of fetomaternal outcome with the time interval between onset of fit to delivery and onset of fit to start of anticonvulsant, in eclampsia patients, from April 2001 to October 2002 in the department of Obstetrics and Gynecology, B. P. Koirala Institue of Health Sciences (BPKIHS), Dharan.

Of the 56 total cases, $22(39.2 \%)$ patients reached the health facility within 3 hours of the onset of fits, and $5(8.9 \%)$ after 12 hours. Twenty-five patients $(\mathbf{4 4 . 6 \% )}$ were first managed in different health care centers while $31(55.4 \%)$ came directly to BPKIHS, Dharan. Maternal complications occurred more frequently in those with fit to delivery time interval and fit to start of anticonvulsant time interval of more than 12 hours. Diazepam was the main anticonvulsant used in other health service facilities while in BPKIHS, 32 (57.1\%) patients were given magnesium sulphate and $24(42.9 \%)$ phenytoin. There were 2 maternal deaths, which occurred in patients in whom the time interval between the onset of fit to delivery and the start of anticonvulsant was more than 24 hours. Seven patients presented with intrauterine fetal deaths and there were 2 neonatal deaths.

Eclampsia is associated with poor fetomaternal outcome. The fetomaternal complications are increased when the fit to delivery time interval and fit to start of anticonvulsant time interval is prolonged. Rational use of appropriate anticonvulsants along with safe delivery should be promoted for eclampsia patients.

Key Words: Eclampsia, fetomaternal outcome.

\section{INTRODUCTION}

Eclampsia is the occurrence of seizures in a woman with preeclampsia that cannot be attributed to other causes. Preeclampsia is a pregnancy specific syndrome of reduced organ perfusion secondary to vasospasm and endothelial activation. About fifty percent of the seizures occur before the onset of labor and other fifty percent are equally divided between intrapartum and postpartum period. ${ }^{1}$ Eclampsia is the third commonest cause of maternal mortality, after hemorrhage and infection in the developing countries. ${ }^{2}$ In developed countries with good health care facilities, very low fetomaternal morbidities and mortalities are reported. ${ }^{3}$ Eclamptic fits accounted for $27 \%$ of maternal deaths during past four years in BPKIHS, Dharan. Delays in deciding to seek care, reach care and receive appropriate care are the major challenges in the management of these patients in our part of the world.

${ }^{*}$ B.P. Koirala Institute of Health Sciences, Dharan, Nepal.

Address for correspondence : Dr. Anjana Karki Rayamajhi 


\section{MATERIALS AND METHODS}

A cross-sectional hospital based study was done from $1^{\text {st }}$ Baisakh 2058 to 30 ${ }^{\text {th }}$ Asoj 2059 (April 2001 to October 2002) in the department of Obstetrics and Gynecology, BPKIHS, Dharan. Patient's baseline characteristics, time of occurrence of first seizure, time taken to reach the health care center and BPKIHS, Dharan; anticonvulsant used, time of start of anticonvulsants, fit to delivery interval and maternal and fetal outcomes till the time of discharge were analyzed.

\section{RESULTS}

A total of 56 patients were treated for eclampsia during this period. Total deliveries during that period were 8492 , giving a frequency of eclampsia of about 1 in 151 deliveries (0.66\%). First fit occurred in the hospital in 2 admitted patients while rest were admitted with eclampsia. Intrapartum ecalmpsia (IPE) occurred in 25 patients, antepartum eclampsia (APE) in 16 ,postpartum eclampsia (PPE) in 10 while 5 were admitted in the postpartum period in whom the fit had started before delivery of the baby (PPadm). Of these 5 postpartum admissions, 3 had delivered at home while 2 in primary health centers. Gestational age ranged from 30 weeks to 43 weeks, with a mean of 35 weeks.

Majority of the patients were primigravidas, 13 adolescent mothers, and 22 were residents of Sunsari district where BPKIHS is located.

Twenty-five patients $(44.6 \%)$ were treated partially outside in health care facilities of different levels while $31(55.4 \%)$ patients were brought directly to BPKIHS, Dharan.

The time taken to reach the first treatment center after the onset of fit ranged from half an hour to 48 hours. Among referred patients $52 \%$ had reached the health facility by 3 hours while in 2 patients time taken was more than 12 hours after the onset of fits. This group of patients obviously took additional time to reach BPKIHS finally. Among 31 patients coming directly to BPKIHS, $31 \%$ had reached by 3 hours while in 3 the time taken was more than 12 hours.

Table I : Maternal baseline characteristics $(\mathrm{n}=56)$

\begin{tabular}{ll|l|l}
\hline \multicolumn{1}{c|}{ Eclampsia } & \multicolumn{1}{c|}{ Age Years } & \multicolumn{1}{c}{ Parity } & \multicolumn{1}{c}{ Address } \\
\hline IPE $=25(45 \%)$ & $15-19=13$ & Nulliparous (43) & Sunsari (22) \\
\hline $\mathrm{APE}=16(28 \%)$ & $20-24=26$ & Multiparous (13) & Jhapa (10) \\
\hline $\mathrm{PPE}=10(18 \%)$ & $25-29=12$ & & Morang (9) \\
PPAdm. $=5(9 \%)$ & $30-34=1$ & & Saptari (5) \\
& $35-39=4$ & & Siraha (3) \\
& & & Other* (7) \\
\hline
\end{tabular}

* 1 each from Panchthar, Dhankuta \& Dhanusha and 4 from India.

Table II : Referring centers $(\mathbf{n}=25)$

\begin{tabular}{lll}
\hline & Centers & No. \\
\hline Pr. Heath Centers & 4 \\
\hline District hospitals & 9 \\
\hline Zonal hospitals & 7 \\
\hline Private/Semiprivate centers & 5 \\
\hline
\end{tabular}

Table III : Time taken to reach first treatment center

\begin{tabular}{c|c|c}
\hline Time (hrs.) & Referral Centre 25 (44.6\%) & BPKIHS 31 (55.4\%) \\
\hline $0-3 \mathrm{hrs}$ & 13 & 9 \\
\hline $3-6 \mathrm{hrs}$ & 7 & 10 \\
$6-12 \mathrm{hrs}$ & 3 & 9 \\
$>12 \mathrm{hrs}$ & 2 & 3 \\
\hline
\end{tabular}

Table IV : Fetomaternal complications detected on arrival to BPKIHS $(n=56)$

\begin{tabular}{c|c|c|c|c}
\hline Time (hrs.) & IUFD & Abruption & Aspiration & Coma \\
\hline $0-6(17)$ & 1 & 0 & 2 & 0 \\
\hline $6-12(18)$ & 1 & 1 & 1 & 0 \\
$12-24(16)$ & 3 & 1 & 3 & 1 \\
$>24(5)$ & 2 & 0 & 2 & 3 \\
\hline
\end{tabular}


Table V : Maternal outcome - fit to delivery time interval $(n=41)^{*}$

\begin{tabular}{c|c|c|cc|c}
\hline Time (hrs.) & Death & Coma >24 hrs & Pneum & LSCS & Psych \\
\hline $0-6(14)$ & 0 & 2 & 1 & 10 & 2 \\
\hline $6-12(11)$ & 0 & 3 & 2 & 5 & 1 \\
\hline $12-24(14)$ & 0 & 4 & 1 & 10 & 2 \\
\hline$>24(2)$ & 1 & 1 & & 1 & 0 \\
\hline
\end{tabular}

* APE+IPE - Delivered in BPKIHS

Pneum = pneumonia, Psych $=$ puerperal psychosis, LSCS - lower segment caeserean section

Table VI : Maternal outcome - fit to start of anticonvulsants $(\mathbf{n}=15)^{* *}$

\begin{tabular}{c|cc|cc|c}
\hline Time (hrs.) & Death & Coma >24 hrs & Pneum. & Psych. & Renal Failure \\
\hline $0-6(3)$ & 0 & 0 & 1 & 0 & 0 \\
\hline $6-12(7)$ & 0 & 3 & 1 & 1 & 0 \\
$12-24(2)$ & 0 & 0 & 1 & 0 & 0 \\
$>24(3)$ & 1 & 2 & 1 & 1 & 1 \\
\hline
\end{tabular}

** PPE+PPadm - puerperal patients

Pneum = pneumonia, Psych $=$ psychosis

Table VII : Major anticonvulsant used

\begin{tabular}{lc|c|cc}
\hline \multicolumn{1}{c|}{ Treatment center } & Magsulph & Phenytoin & Diazepam & None \\
\hline Pr. Heath center & 0 & 0 & 2 & 2 \\
\hline District hospital & 0 & 1 & 1 & 5 \\
\hline Zonal hospital & 1 & 0 & 1 & 4 \\
Private centres & 0 & 0 & 1 & 0 \\
BPKIHS & 32 & 24 & 0 & 2 \\
\hline
\end{tabular}

Table VIII : Fetal outcome - fit to delivery time interval $(n=41)^{*}$

\begin{tabular}{cc|cc}
\hline Time (hrs.) & SB & NND & NICU Admission \\
\hline $0-6(14)$ & 1 & 1 & 4 \\
\hline $6-12(11)$ & 1 & 0 & 2 \\
$12-24(14)$ & 3 & 1 & 6 \\
$>24(2)$ & 2 & 0 & 0 \\
\hline
\end{tabular}

* APE+IPE - Delivered in BPKIHS

$S B=$ stillbirth, $N N D=$ neonatal death, NICU = neonatal intensive care unit

At the time of arrival in BPKIHS, fetomaternal complications detected in relation to time interval with onset of fit showed increased frequency of intrauterine fetal deaths, abruptio placentae, signs of maternal aspiration and deep coma in those where the time interval from onset of fit to hospital entry was more than 12 hours.

Among 41 patients admitted in BPKIHS before delivery, 1 maternal death occurred in whom fit to delivery interval was more than 24 hours. The persistence of deep coma for more than 24 hours, development of pneumonia and puerperal psychosis were more frequent in those with the time interval of more than 12 hours.

Analysis of maternal outcome in relation to onset of fit to start of anticonvulsants in the postpartum patients admitted in BPKIHS after delivery shows that 1 maternal death occurred in that patient with time interval of more than 24 hours.
Similarly other complications were more frequent in those with time interval of more than 12 hours.

Regarding the use of anticonvulsants, Diazepam infusion and intravenous boluses were mainly used in referring centers while 18 out of $25(72 \%)$ patients referred from these centers were not given any anticonvulsants. In BPKIHS, $57.1 \%$ were given Magnesium sulphate and $42.9 \%$ Phenytoin as the main anticonvulsant. Recurrence of fits after start of anticonvulsant was seen in 2 patients receiving Phenytoin and 1 receiving Magnesium sulphate.

A total of 43 babies were born to 41 mothers, including 2 sets of twins. There were 7 intrauterine fetal deaths and 2 neonatal deaths giving a perinatal mortality of 21 percent. The 2 neonates died due to complications of prematurity. Both the mothers had received Phenytoin. Neonatal intensive care support was needed in 12 babies. 


\section{DISCUSSION}

Global estimates of the incidence of eclampsia project about 50,000 maternal deaths due to eclamptic fits each year. ${ }^{4}$ Eclampsia is now an uncommon disease in the developed countries. The incidence in USA for 1990 to 2000 was approximately 1 in 2300 deliveries while Douglas and Redman cited an incidence of 1 in 2000 deliveries for UK in 1992. ${ }^{5}$ Chan and Ngai have reported a constant incidence of eclampsia from 1983 to 1993 of 2 per 10,000 deliveries in Tsan Yuk Hospital of University of Hong Kong. ${ }^{6}$ In Rajavithi Hospital Bangkok where magnesium sulphate is in use as the anticonvulsant since 1977 , the incidence of eclampsia is reported as 1 in 1,857 deliveries. ${ }^{7}$ In developing countries where health care services are not accessible to all, eclampsia is still rampant. Bathla et al report an incidence similar to the present study of 1 in 139 deliveries from two urban hospitals in India. ${ }^{8}$

Intrapartum eclampsia was found to be the commonest condition (45\%) and postpartum eclampsia least common $(18 \%)$ in the present study while Bathla et al have reported antepartum eclampsia as most frequent. ${ }^{8}$ In the hospital of University of Hong Kong, where the incidence of eclampsia quite low, postpartum eclampsia is more frequently encountered. ${ }^{6}$ Katz et al report antepartum eclampsia as more common than intrapartum and postpartum eclampsia in their study from two tertiary care hospitals in USA. ${ }^{9}$

Late entry into the hospital is a major problem in our country and is associated with more complications. The two maternal deaths that occurred in these patients were among those brought to the hospital very late. One mother who died had fit to hospitalization interval of 26 hours and fit to delivery interval of 32 hours. The other maternal death was in the patient who had fits for 2 days prior to delivery at home and was brought 12 hours after delivery to the hospital. Bathla et al in their study from India had 3 maternal deaths out of 66 cases of eclampsia, all in patients who were brought very late to the hospital. ${ }^{8}$ Recurrent seizures and prolonged interval from onset of fits to institution of therapy is associated with a poorer fetomaternal outcome. Lucas et al have reported the association of recurrent seizures with increased maternal morbidity. ${ }^{10}$ The delay in deciding to seek and reach care are related to a number of factors, like lack of health awareness and education, sociocultural taboos, financial constraints etc. Seizures may be the first sign of eclampsia. Katz et al report in a study from USA, that $60 \%$ of eclampsia patients had seizures as the first sign of eclampsia. They found that out of 28 antepartum eclampsia 23 had seizures at home though these patients were brought immediately to the hospital. They conclude that it may not possible to prevent eclampsia in many instances. ${ }^{9}$
Among the 25 patients referred from outside health care facilities, only 7 had received some anticonvulsants there in our study. Four had been given boluses of intravenous Diazepam, 1 infusion of Diazepam, one each Phenytoin and Magnesium sulphate. Among the referred patients, 4 had cesarean deliveries in these health care centers, which indicates that these centers were capable of providing emergency obstetric care. In BPKIHS, Dharan, 32 patients were given Magnesium sulphate and 24 Phenytoin, as the anticonvulsant. Eclampsia Trial Collaborative Group has reported the superiority of Magnesium sulphate over both Phenytoin and Diazepam for control of convulsions. ${ }^{11}$ In UK Diazepam has been popular since 1970s and Phenytoin since early 1990s while Magnesium sulphate use remained uncommon till late 1990. ${ }^{12}$ In a survey done in 1992 in UK only 2\% of women with eclampsia received Magnesium sulphate while up till 1998 Diazepam was most widely used and Phenytoin preferred by a quarter of physicians. ${ }^{13}$ The survey in 1998 showed that about $60 \%$ of treating physicians liked to use Magnesium sulphate even after the landmark trial establishing the superiority of Magnesium sulphate over both Diazepam and Phenytoin was published in 1995. ${ }^{12}$ In USA, Magnesium sulphate has been widely used for decades now and is the preferred anticonvulsant even for prophylactic use in severe pre-eclampsia. ${ }^{14,15}$ In centers of urban India like Delhi about 58\% of eclampsia had received Phenytoin as the major anticonvulsant in a study done in 19971998. ${ }^{8}$ In Nepal, Diazepam is still widely used in many health care facilities as an anticonvulsant. Similarly in Dhaka, Bangladesh where probably health facilities and problems are similar as in Nepal, a clinical trial was conducted in 1995-96 to compare Magnesium sulphate and Diazepam in the management of eclampsia. The authors found Magnesium sulphate to be a superior drug but it was not available in the primary health care facilities..$^{16}$ Magnesium sulphate has become easily available in Dharan since last one year only.

There were 2 maternal deaths in the present study. Late entry to the hospital is a major problem in our part of the world. Raman and Rao in their study from Hyderabad, India found 16 deaths in 562 cases of eclampsia. ${ }^{17}$ In centers with good health facilities maternal deaths are rare in eclampsia patients. Katz et al had no maternal deaths and no permanent morbidities among 53 eclampsia patients in their study from USA.

Perinatal mortality and morbidity is another concern in eclampsia patients, as the definitive treatment demands termination of pregnancy. In the present study, perinatal mortality was 21 percent, with 7 patients admitted with intrauterine fetal deaths, and 2 neonatal deaths. In different studies from centers of India and Bangladesh perinatal mortality has been reported between 30 to 40 percent. ${ }^{8,16,17}$ The 
perinatal mortalities in centers with good neonatal care backup are reported as low as 7 to 11 percent. , $, 7,9^{-}$

Maternal complications and perinatal loss were more in patients brought very late to the hospital in the present study. The basic management aims in eclampsia include attaining control of convulsions, control of blood pressure and safe delivery within a reasonable period of time. Rational use of appropriate anticonvulsants along with safe delivery should be promoted for these patients at all health service levels. Referral to a better-equipped center when necessary should be accompanied by appropriate emergency obstetric care in these patients. Health education and public awareness regarding decision to seek care on time should be promoted at all levels.

\section{REFERENCES}

1. Hypert ensi ve di sorders i n pregnancy. I n: Curni nghamFG Gant $\mathrm{NF}$, Levono $\mathrm{J}, \mathrm{G} I$ st rap LC and Wenst romKD Eds. WI I i ans Costetri cs 2Ft ed. MtGawt H II , 2001 567- 618.

2. MynenbaJ . Manesi umsul phatef or ecl anpsi a:putti ngevi dence i nto cl i ni cal practi ce. Cent Afr J Med 2000 J un 46 (6): 66- 9.

3. Chi en PF, Khan KS, Arnott $\mathrm{N}$ Magnesi umsul phate in the treatnent of ecl anpsi a and pre-ecl anpsi a: an overvi ewof the evi dence fromrandonized tri al s. Br J Cbstet Gynaecol 1996; 103:1085- 91

4. Ef fecti veness Update, DFI D, August 1998.

5. Dougl as KA Rednan CKG ECl anpsi a i n the Uni ted K ngdom BM 1994; 309:1395 - 1400.

6. Chan YM Ngai SW Ecl anpsi a ñan $\mathbb{1}$ year experi ence. HM 1998; 4: 203- 7.
7. Chi nayon P. Q i ni cal managenent and out cone of ecl ampsi a at Raj avi thi Hospi tal . J Med Assoc Thai 998; 81 579- 85.

8. Bathl a S, Sunej a A, Gul eri a K, Agar wal N Dilanti n as anti convul sant i n ecl anpsi a. J I MA 2000; 17:341 45.

9. Katz L, Farner R, Kul I er J A Pre ecl anpsi a i nt o ecl anpsi a: towards a new paradi gm AmJ Costet Gynecol 2000; 182: 1389- 96.

10. Lucas LS, J ordan ET. Phenytoi nas an al ter nati ve for preecl anpsi a.J Cbstet Gynecol Neonatal Nurs 1997; 26: 263- 9.

11. Ed anpsi aTri al Col I aborati veGroup. Wi chanti convul sant for uonen wi th ecl anpsi a? Evi dence fromthe col I abor at i ve ecl anpsi a tri al . Lancet 1995; 345:4455- 63.

12. Gul nezogl uAMDul ey L. Use of ant i convul sants i necl anpsi a and pre-ecl anpsi a: survey of obstetri ci ans i n the Uni ted K ngdomand Republ i c of I rel and. BM 1998; 316: 975- 76.

13. Hitt on J D, J anes DK, Sti rrat GM Dougl as KA, Rednan CVG Managenent of sever e pre-ecl anpsi a and ecl anpsi a by UK consul tants. Br J Cbstet Gynaecol 1992; 99: 554- 56.

14. Dul ey L, J ohanson R Magnesi umsul phat e f or pre ecl anpsi a and ecl ampsi a: theevi dence so far. Br.J Obstet Gynecol B94; 101: 565- 67.

15. ChuaS, Redhan CNAre prophyl act i c ant i convul sants requi red i n severe pre-ecl anpsi a? Lancet 199ł 337: 250-51

16. Shansuddi n I, Rouf S, Khan JH Tananna S, Hussai n AZ, Sansuddi n AK Magnesi umsul phate versus di azepami n nanagenent of ecl anpsi a. Bangl adesh Med Res Counc Bul I 1998; 24: 43- 8.

17. Raman M, Rao CA Magnesi umsul f ate as an anti convul sant i n ecl anpsi a. I nt J Gynaecol Cbst et 1995; 49: 289- 98.

\section{(r)

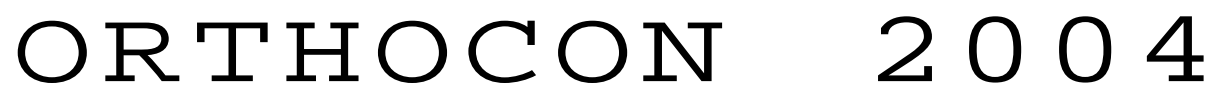 \\ Kathmandu, Nepal \\ 2 - 4th April, 2004 \\ Jaintl y orgari zed by \\ Nepal Orthopaedic Association \\ President \\ Dr. Achyut Rajbhandari \\ Orthopaedica Belgica \\ President \\ BVOT Dr. Jan Victor \\ SORBCOT Dr. Jacques Magotteaux \\ Nepal Orthopaedic Association (NOA) \\ NMA Building, Siddhi Sadan, Exhibition Road \\ GPO Box: 189, Kathmandu, Nepal \\ Tel.: 4225860, 4231825, Fax: 977-1-4225300 \\ Email: noa@healthnet.org.np}

